\title{
Comparative Study between The Role of Two dimensional and Three Dimensional Ultrasound in Assessment of Fetal Central Nervous System Congenital Anomalies
}

Yahia Zakaria Ali ${ }^{1, *}$ MSc., Abd-El Monsef Abd-El Hamid Seddik ${ }^{1}$ MD. and Awad Mahmoud Awad ${ }^{1}$ MD.

* Corresponding Author:

Yahia Zakaria Ali

dr_yahia_zakaria@yahoo.com

Received for publication April 09, 2021; Accepted July 31, 2021; Published online July 31, 2021.

Copyright The Authors published by Al-Azhar University, Faculty of Medicine, Cairo, Egypt. Users have the right to read, download, copy, distribute, print, search, or link to the full texts of articles under the following conditions: Creative Commons Attribution-Share Alike 4.0 International Public License (CC $B Y-S A$ 4.0).

doi: 10.21608/aimj.2021.69313.1445

${ }^{1}$ Department of Obstetrics \& Gynecology, Faculty of Medicine, AlAzhar University, Cairo, Egypt.

\begin{abstract}
Background: Three dimensional ultrasound (3D US) has become the new standard in prenatal diagnosis of fetal congenital anomalies. This technique enables detailed examination of the fetal anatomy and higher quality depiction of congenital anomalies. Furthermore, four dimensional ultrasound (4D US) enables visualization of more details regarding the dynamics of small anatomical structures. Using the advantages of this technology, a physiologic pattern of embryonic or fetal motor development was made.

Objective: This study aimed to evaluate the role of three dimensional (3D) ultrasound compared with two dimensional (2D) ultrasound in diagnosis of fetal central nervous system congenital malformations.

Patients and Methods: This Prospective study was performed on total 100 patients with gestational age from 18 weeks to 24 weeks who underwent $2 \mathrm{D}$ ultrasound then examined by $3 \mathrm{D}$ ultrasound at Obstetrics and Gynecology Department, Bab el-Sheria, Al-Azhar University Hospital.

Results: Statistical analysis revealed that the most common neurological malformations detected were Holoprosencephaly and Anencephaly which had significant high agreement between 2D and 3D regarding their diagnosis. There was significant agreement between 2D and 3D regarding the congenital fetal spinal and cranial malformations. The 2D and 3D ultrasound provided equal diagnostic information in microcephaly while 3D US provided more diagnostic information than 2D US for Choroid plexus cyst, agenesis of the corpus callosum and spina bifida.

Conclusion: In comparison with 2D US, 3D US improves the diagnostic capability by illustrating more diagnostic details in evaluation of malformations of the fetus, especially in visualization of fetal malformations of the small cranial anomalies and spina bifida.
\end{abstract}

Keywords: Fetal; Central Nervous System; Congenital Anomalies; Two dimensional; Three dimensional Ultrasound.

Disclosure: The authors have no financial interest to declare in relation to the content of this article. The Article Processing Charge was paid for by the authors.

Authorship: All authors have a substantial contribution to the article.

\section{INTRODUCTION}

Fetal congenital anomalies risk is reported to be about $2 \%$ to $3 \%$ regardless of their prior history, family history, maternal age or lifestyle. This risk increases in some patients (high risk pregnancy). Among these factors that increase the risk of fetal congenital anomalies are advanced maternal age, history of drug intake (teratogenic drugs) during first trimester, maternal smoking \& alcoholism, exposure to radiation, prior history of recurrent abortion or delivery of malformed fetus . ${ }^{7}$

Congenital deformities represent $20-25 \%$ of perinatal demises. Presently, numerous hereditary and different issues can be diagnosed early in pregnancy. Antenatal diagnosis utilizes different non-invasive and invasive procedures to decide the wellbeing of the condition or any anomaly in an unborn fetus. ${ }^{1}$
The neural system malformation is one of common congenital anomalies encountered in pregnancy. ${ }^{16}$

They represent about $0.3-1 \%$ of all live births. During prenatal anomaly scan, detection of CNS malformation is important especially these anomalies have a poor prognosis and also associated with genetic syndromes or chromosomal anomalies. ${ }^{15}$

The CNS development start from 3 weeks to 20 weeks of intrauterine fetal life. Often all neural anomalies are a result from defect in embryogenesis at certain points of development. Ultrasongraphy can detect many CNS anomalies in the first and an early second trimester. Some of them develop or become obvious at end of pregnancy. The earlier in detection, the more time available for the parents and clinician to plan the outcome of pregnancy. Extensive and severe life threating disorders give reason for early 
termination of pregnancy, and detection of minor disorders helps everybody to be prepared and reassured for post-delivery management. ${ }^{4}$

Two dimensional (2D) ultrasonography, antenatal detection of many types of central nervous system anomalies have been detected. 2D sonography can diagnose many fetal abnormalities. Due to defects in third dimension, some of them cannot be seen with the conventional technique, this depend on the defect type and the limitations of fetal position. ${ }^{10}$

Three dimensional ultrasound (3DUS) has become the new good standard in intrauterine diagnosis of fetal congenital anomalies. This technique allowing fetal anatomical examination in details and higher quality illusteration of congenital anomalies. Dynamics of the small anatomical structures can be visualized in more details via four dimensional ultrasound (4D US). The advantages of this technology can be used in assesment of an embryonic physiological pattern or fetal motor development. ${ }^{17}$

The aim of this study is to evaluate the role of three dimensional (3D) ultrasound compared with two dimensional (2D) ultrasound in diagnosis of fetal central nervous system congenital malformations.

\section{PATIENTS AND METHODS}

This prospective study which was performed at Obstetrics and Gynecology Department, Al-azhar University Hospital included 100 patients with gestational age from 18 weeks to 24 weeks by 2D ultrasound then examined by $3 \mathrm{D}$ ultrasound with the following criteria:

Inclusion criteria included Age of 18 to 40 years old pregnant women and pregnant women Suspected to have fetal CNS malformations during routine antenatal obstetric evaluation.

Exclusion criteria included Women with no suspected fetal neurological anomalies.

This study was conducted regarding ethical committee Faculty of medicine, Al-Azhar University after informed consent was taken from all cases after complete demonstration of the study purpose before rolling in this study.

Initially, traditional 2DUS was routinely performed. Assessment of fetus include (The heart, thorax, abdominal wall, abdominal viscera, limbs, spines, head and neck).

After complete examination by the 2D sonography, initial diagnosis was done based on the detected findings. After intial diagnosis, patients were undergoing evaluation by 3DUS to obtain data by 3D imaging compared to the 2D findings, and if the 3D imaging displayed any superiority in diagnosis.

A 3D US volume was taken to scan all regions, as well as the area of interest when 2DUS detected pictures with various filter settings was used to differentiate between the soft tissue $\&$ bony features. The $3 \mathrm{D}$ images was compared with the $2 \mathrm{D}$ images.
The results obtained with $2 \mathrm{D}$ and $3 \mathrm{D}$ US was compared according to identification, localization, size and depth of the malformation detected.

Ethical Considerations: The patient data were anonymous. Data presentation was not be by the patient name but by diagnosis and patient confidentiality was protected. Study protocol was submitted for approval by ethics committee of Faculty of Medicine - AL Azhar University.

\section{Statistical analysis:}

The collected data were coded, tabulated, and statistically analyzed using IBM SPSS statistics (Statistical Package for Social Sciences) software version 22.0, IBM Corp., Chicago, USA, 2013. Quantitative normally distributed data described as mean \pm SD (standard deviation) after testing for normality using Shapiro-Wilk test, then compared using independent t-test if normally distributed and Mann Whitney test if not normally distributed, while Pearson test was used for correlations. Qualitative data described as number and percentage and compared using Chi square test and Fisher's exact test for variables with small expected numbers. Log rank test was used to compare abortion rate. The level of significance was taken at $\mathrm{P}$ value $<0.050$ was significant, otherwise was non-significant.

\section{RESULTS}

The most frequent neurological malformations were Holoprosencephaly and Anencephaly (Table 1).

\begin{tabular}{|l|c|c|}
\hline \multicolumn{1}{|c|}{ Diagnosis } & 3D & 2D \\
\hline Normal & $12(12.0 \%)$ & $17(17.0 \%)$ \\
\hline Holoprosencephaly & $14(14.0 \%)$ & $13(13.0 \%)$ \\
\hline Anencephaly & $13(13.0 \%)$ & $13(13.0 \%)$ \\
\hline Dandy-Walker malformation & $10(10.0 \%)$ & $10(10.0 \%)$ \\
\hline Occipital encephalocele & $8(8.0 \%)$ & $7(7.0 \%)$ \\
\hline Agenesis of the Corpus Callosum & $7(7.0 \%)$ & $7(7.0 \%)$ \\
\hline Microcephaly & $6(6.0 \%)$ & $6(6.0 \%)$ \\
\hline Hydrocephalus & $6(6.0 \%)$ & $6(6.0 \%)$ \\
\hline Choroid plexus cyst & $5(5.0 \%)$ & $5(5.0 \%)$ \\
\hline Spina bifida (meningocele) & $5(5.0 \%)$ & $3(3.0 \%)$ \\
\hline Congenital Scoliosis & $4(4.0 \%)$ & $4(4.0 \%)$ \\
\hline Chiari malformation & $4(4.0 \%)$ & $4(4.0 \%)$ \\
\hline Schizencephaly & $3(3.0 \%)$ & $3(3.0 \%)$ \\
\hline Hydranencephaly & $3(3.0 \%)$ & $2(2.0 \%)$ \\
\hline
\end{tabular}

Table 1: Diagnosis among the studied cases

There was significant moderate agreement between 2D and 3D regarding neurological anomaly diagnosis (Table 2).

\begin{tabular}{|c|c|c|c|c|}
\hline \multirow{2}{*}{ 2D } & \multicolumn{2}{|c|}{ 3D } & \multirow{2}{*}{\multicolumn{2}{|c|}{ Total }} \\
\hline & \multirow{2}{*}{$\begin{array}{c}\text { Positive } \\
83(83.0 \%) \underline{\text { TP }}\end{array}$} & Negative & & \\
\hline Positive & & $0(0.0 \%) \underline{\mathbf{F P}}$ & \multicolumn{2}{|c|}{$83(83.0 \%)$} \\
\hline Negative & $5(5.0 \%) \stackrel{\mathbf{E N}}{\underline{N}}$ & $12(12.0 \%) \stackrel{\mathrm{TN}}{\mathrm{T}}$ & \multicolumn{2}{|c|}{$17(17.0 \%)$} \\
\hline Total & $88(88.0 \%)$ & $12(12.0 \%)$ & \multicolumn{2}{|c|}{$100(100.0 \%)$} \\
\hline \multicolumn{2}{|c|}{ Kappa } & 0.799 & $\mathbf{P}$ & $<0.001^{*}$ \\
\hline
\end{tabular}

Table 2: Agreement between 2D and 3D regarding neurological anomaly diagnosis 
There was significant high agreement between $2 \mathrm{D}$ and 3D regarding Holoprosencephaly diagnosis (Table 3).

\begin{tabular}{|c|c|c|c|c|}
\hline \multirow{2}{*}{ 2D } & \multicolumn{2}{|c|}{ 3D } & \multirow{2}{*}{\multicolumn{2}{|c|}{ Total }} \\
\hline & Positive & Negative & & \\
\hline Positive & $13(13.0 \%) \underline{\text { TP }}$ & $0(0.0 \%) \underline{\mathrm{FP}}$ & & $3.0 \%)$ \\
\hline Negative & $1(1.0 \%) \stackrel{\mathbf{F N}}{-}$ & $86(86.0 \%) \underline{\mathbf{T N}}$ & & $7.0 \%)$ \\
\hline Total & $14(14.0 \%)$ & $86(86.0 \%)$ & & $00.0 \%)$ \\
\hline \multicolumn{2}{|c|}{ Kappa } & 0.957 & $\mathbf{P}$ & $<0.001 *$ \\
\hline
\end{tabular}

Table 3: Agreement between 2D and 3D regarding Holoprosencephaly diagnosis

There was significant perfect agreement between 2D and 3D regarding Anencephaly diagnosis (Table 4).

\begin{tabular}{|c|c|c|c|c|}
\hline \multirow{2}{*}{ 2D } & \multicolumn{2}{|c|}{ 3D } & \multirow{2}{*}{\multicolumn{2}{|c|}{ Total }} \\
\hline & Positive & Negative & & \\
\hline Positive & $13(13.0 \%) \underline{\text { TP }}$ & $0(0.0 \%) \stackrel{\mathbf{F P}}{0}$ & \multicolumn{2}{|c|}{$13(13.0 \%)$} \\
\hline Negative & $0(0.0 \%) \stackrel{\mathbf{F N}}{2}$ & $87(87.0 \%) \stackrel{\text { TN }}{ }$ & \multicolumn{2}{|c|}{$87(87.0 \%)$} \\
\hline Total & $13(13.0 \%)$ & $87(87.0 \%)$ & \multicolumn{2}{|c|}{$100(100.0 \%)$} \\
\hline Kappa & \multicolumn{2}{|r|}{1.000} & $\mathbf{P}$ & $<0.001 *$ \\
\hline
\end{tabular}

Table 4: Agreement between 2D and 3D regarding Anencephaly diagnosis

There was significant perfect agreement between 2D and 3D regarding Dandy-Walker malformation diagnosis (Table 5)

\begin{tabular}{|c|c|c|c|c|}
\hline \multirow{2}{*}{ 2D } & \multicolumn{2}{|c|}{ 3D } & \multirow{2}{*}{\multicolumn{2}{|c|}{ Total }} \\
\hline & Positive & Negative & & \\
\hline Positive & $10(10.0 \%) \underline{\text { TP }}$ & $0(0.0 \%) \underline{\text { EP }}$ & \multicolumn{2}{|c|}{$10(10.0 \%)$} \\
\hline Negative & $0(0.0 \%) \stackrel{\mathbf{F N}}{\underline{N}}$ & $90(90.0 \%)^{\mathbf{T N}}$ & \multicolumn{2}{|c|}{$90(90.0 \%)$} \\
\hline Total & $10(0.0 \%)$ & $90(90.0 \%)$ & \multicolumn{2}{|c|}{$100(100.0 \%)$} \\
\hline Kappa & \multicolumn{2}{|c|}{1.000} & $\mathbf{P}$ & $<0.001 *$ \\
\hline
\end{tabular}

Table 5: Agreement between 2D and 3D regarding Dandy-Walker malformation diagnosis

There was significant high agreement between 2D and 3D regarding Occipital encephalocele diagnosis (Table 6).

\begin{tabular}{|c|c|c|c|c|}
\hline \multirow{2}{*}{ 2D } & \multicolumn{2}{|c|}{ 3D } & \multirow{2}{*}{\multicolumn{2}{|c|}{ Total }} \\
\hline & Positive & Negative & & \\
\hline Positive & $7(7.0 \%) \underline{\text { TP }}$ & $0(0.0 \%) \underline{\mathbf{F P}}$ & \multicolumn{2}{|c|}{$7(7.0 \%)$} \\
\hline Negative & $1(1.0 \%) \stackrel{\mathbf{F N}}{=}$ & $92(92.0 \%) \stackrel{\text { TN }}{=}$ & \multicolumn{2}{|c|}{$93(93.0 \%)$} \\
\hline Total & $8(8.0 \%)$ & $92(92.0 \%)$ & \multicolumn{2}{|c|}{$100(100.0 \%)$} \\
\hline Kappa & \multicolumn{2}{|r|}{0.928} & $\mathbf{P}$ & $<0.001 *$ \\
\hline
\end{tabular}

Table 6: Agreement between 2D and 3D regarding Occipital encephalocele diagnosis

There was significant perfect agreement between 2D and 3D rsegarding Agenesis of the Corpus Callosum diagnosis (Table 7).

\begin{tabular}{|c|c|c|c|c|}
\hline \multirow{2}{*}{ 2D } & \multicolumn{2}{|c|}{ 3D } & \multirow{2}{*}{\multicolumn{2}{|c|}{ Total }} \\
\hline & Positive & Negative & & \\
\hline Positive & $7(7.0 \%) \stackrel{\text { TP }}{-}$ & $0(0.0 \%) \stackrel{\mathbf{F P}}{\underline{4}}$ & \multicolumn{2}{|c|}{$7(7.0 \%)$} \\
\hline Negative & $0(0.0 \%)^{\mathrm{FN}}$ & $93(93.0 \%)^{\mathbf{T N}}$ & \multicolumn{2}{|c|}{$93(93.0 \%)$} \\
\hline Total & $7(7.0 \%)$ & $93(93.0 \%)$ & \multicolumn{2}{|c|}{$100(100.0 \%)$} \\
\hline Kappa & \multicolumn{2}{|c|}{1.000} & $\mathbf{P}$ & $<0.001 *$ \\
\hline
\end{tabular}

There was significant perfect agreement between 2D and 3D regarding Microcephaly diagnosis (Table 8).

\begin{tabular}{|c|c|c|c|c|}
\hline \multirow{2}{*}{$2 D$} & \multicolumn{2}{|c|}{ 3D } & \multirow{2}{*}{\multicolumn{2}{|c|}{ Total }} \\
\hline & Positive & Negative & & \\
\hline Positive & $6(6.0 \%) \stackrel{\text { TP }}{ }$ & $0(0.0 \%)^{\mathrm{FP}}$ & \multicolumn{2}{|c|}{$6(6.0 \%)$} \\
\hline Negative & $0(0.0 \%) \underline{\mathbf{E N}}$ & $94(94.0 \%) \underline{\mathrm{TN}}$ & \multicolumn{2}{|c|}{$94(93.0 \%)$} \\
\hline Total & $6(6.0 \%)$ & $94(94.0 \%)$ & \multicolumn{2}{|c|}{$100(100.0 \%)$} \\
\hline \multicolumn{2}{|c|}{ Kappa } & 1.000 & $\mathbf{P}$ & $<0.001 *$ \\
\hline
\end{tabular}

Table 8: Agreement between 2D and 3D regarding Microcephaly diagnosis

There was significant perfect agreement between 2D and 3D regarding Hydrocephalus diagnosis (Table 9).

\begin{tabular}{|c|c|c|c|c|}
\hline \multirow{2}{*}{ 2D } & \multicolumn{2}{|c|}{ 3D } & \multirow{2}{*}{\multicolumn{2}{|c|}{ Total }} \\
\hline & Positive & Negative & & \\
\hline Positive & $6(6.0 \%) \underline{\mathrm{TP}}$ & $0(0.0 \%) \underline{\mathrm{FP}}$ & \multicolumn{2}{|c|}{$6(6.0 \%)$} \\
\hline Negative & $0(0.0 \%) \stackrel{\mathrm{FN}}{\longrightarrow}$ & $94(94.0 \%) \stackrel{\mathrm{TN}}{-}$ & \multicolumn{2}{|c|}{$94(93.0 \%)$} \\
\hline Total & $6(6.0 \%)$ & $94(94.0 \%)$ & & $0.0 \%)$ \\
\hline \multicolumn{2}{|c|}{ Kappa } & 1.000 & $\mathbf{P}$ & $<0.001 *$ \\
\hline
\end{tabular}

Table 9: Agreement between 2D and 3D regarding

Hydrocephalus diagnosis

There was significant perfect agreement between 2D and $3 \mathrm{D}$ regarding Choroid plexus cyst diagnosis (Table 10).

\begin{tabular}{|c|c|c|c|c|}
\hline \multirow{2}{*}{ 2D } & \multicolumn{2}{|c|}{ 3D } & \multirow{2}{*}{\multicolumn{2}{|c|}{ Total }} \\
\hline & Positive & Negative & & \\
\hline Positive & \multirow{2}{*}{$\frac{5(5.0 \%) \underline{\underline{P}}}{0(0.0 \%) \underline{\mathrm{EN}}}$} & 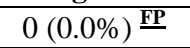 & \multicolumn{2}{|c|}{$5(5.0 \%)$} \\
\hline Negative & & $95(95.0 \%) \stackrel{\mathrm{TN}}{-}$ & \multicolumn{2}{|c|}{$95(95.0 \%)$} \\
\hline Total & $5(5.0 \%)$ & $95(95.0 \%)$ & \multicolumn{2}{|c|}{$100(100.0 \%)$} \\
\hline \multicolumn{2}{|c|}{ Kappa } & 1.000 & $\mathbf{P}$ & $<0.001 *$ \\
\hline
\end{tabular}

Table 10: Agreement between 2D and 3D regarding

Choroid plexus cyst diagnosis

There was significant moderate agreement between 2D and 3D regarding Spina bifida (meningocele) diagnosis (Table 11)

\begin{tabular}{|c|c|c|c|c|}
\hline \multirow{2}{*}{ 2D } & \multicolumn{2}{|c|}{ 3D } & \multirow{2}{*}{\multicolumn{2}{|c|}{ Total }} \\
\hline & Positive & Negative & & \\
\hline Positive & $3(3.0 \%) \stackrel{\mathrm{TP}}{\mathrm{T}}$ & $0(0.0 \%) \underline{\mathrm{EP}}$ & \multicolumn{2}{|c|}{$3(3.0 \%)$} \\
\hline Negative & $2(2.0 \%) \frac{\mathrm{FN}}{\mathrm{N}}$ & $95(95.0 \%) \stackrel{\mathrm{TN}}{-}$ & \multicolumn{2}{|c|}{$97(97.0 \%)$} \\
\hline Total & $5(5.0 \%)$ & $95(95.0 \%)$ & \multicolumn{2}{|c|}{$100(100.0 \%)$} \\
\hline \multicolumn{2}{|c|}{ Kappa } & 0.749 & $\mathbf{P}$ & $<0.001 *$ \\
\hline
\end{tabular}

Table 11: Agreement between 2D and 3D regarding Spina bifida (meningocele) diagnosis

There was significant perfect agreement between 2D and $3 \mathrm{D}$ regarding Congenital Scoliosis diagnosis (Table 12).

\begin{tabular}{|c|c|c|c|c|}
\hline \multirow{2}{*}{ 2D } & \multicolumn{2}{|c|}{ 3D } & \multirow{2}{*}{\multicolumn{2}{|c|}{ Total }} \\
\hline & Positive & Negative & & \\
\hline Positive & $4(4.0 \%) \stackrel{\text { TP }}{-}$ & $0(0.0 \%) \underline{\mathbf{F P}}$ & \multicolumn{2}{|c|}{$4(4.0 \%)$} \\
\hline Negative & $0(0.0 \%) \stackrel{\mathbf{F N}}{ }$ & $96(96.0 \%) \stackrel{\text { TN }}{-}$ & \multicolumn{2}{|c|}{$96(96.0 \%)$} \\
\hline Total & $4(5.0 \%)$ & $96(96.0 \%)$ & \multicolumn{2}{|c|}{$100(100.0 \%)$} \\
\hline \multicolumn{2}{|c|}{ Карра } & 1.000 & $\mathbf{P}$ & $<0.001 *$ \\
\hline
\end{tabular}

Table 12: Agreement between 2D and 3D regarding

Congenital Scoliosis diagnosis 
There was significant perfect agreement between 2D and 3D regarding Chiari malformation diagnosis (Table 13).

\begin{tabular}{|c|c|c|c|c|}
\hline \multirow{2}{*}{ 2D } & \multicolumn{2}{|c|}{ 3D } & \multirow{2}{*}{\multicolumn{2}{|c|}{ Total }} \\
\hline & \multirow{2}{*}{$\begin{array}{c}\text { Positive } \\
4(4.0 \%) \underline{\text { TP }}\end{array}$} & Negative & & \\
\hline Positive & & 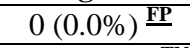 & \multicolumn{2}{|c|}{$4(4.0 \%)$} \\
\hline Negative & $0(0.0 \%) \stackrel{\mathbf{F N}}{-}$ & $96(96.0 \%) \stackrel{\mathbf{T N}}{-}$ & \multicolumn{2}{|c|}{$96(96.0 \%)$} \\
\hline Total & $4(5.0 \%)$ & $96(96.0 \%)$ & & $0.0 \%)$ \\
\hline \multicolumn{2}{|c|}{ Kappa } & 1.000 & $\mathbf{P}$ & $<0.001 *$ \\
\hline
\end{tabular}

Table 13: Agreement between 2D and 3D regarding Chiari malformation diagnosis

There was significant perfect agreement between 2D and 3D regarding diagnosis (Table 14).

\begin{tabular}{|c|c|c|c|c|}
\hline \multirow{2}{*}{ 2D } & \multicolumn{2}{|c|}{ 3D } & \multirow{2}{*}{\multicolumn{2}{|c|}{ Total }} \\
\hline & Positive & Negative & & \\
\hline Positive & $3(3.0 \%) \stackrel{\mathrm{TP}}{\mathbf{T P}}$ & $0(0.0 \%) \stackrel{\mathrm{FP}}{-}$ & \multicolumn{2}{|c|}{$3(3.0 \%)$} \\
\hline Negative & $0(0.0 \%) \stackrel{\mathbf{F N}}{\mathbf{N}}$ & $97(97.0 \%) \underline{\mathbf{T N}}$ & \multicolumn{2}{|c|}{$97(97.0 \%)$} \\
\hline Total & $3(3.0 \%)$ & $97(97.0 \%)$ & \multicolumn{2}{|c|}{$100(100.0 \%)$} \\
\hline Kapp: & \multicolumn{2}{|c|}{1.000} & $\mathbf{P}$ & $<0.001 *$ \\
\hline
\end{tabular}

Table 14: Agreement between $2 \mathrm{D}$ and $3 \mathrm{D}$ regarding diagnosis

There was significant moderate agreement between 2D and 3D regarding Hydranencephaly diagnosis (Table 15).

\begin{tabular}{|l|c|c|}
\hline \multicolumn{1}{|c|}{ Diagnosis } & Equivalent & More \\
\hline Overall & $61(61.0 \%)$ & $39(39.0 \%)$ \\
\hline Holoprosencephaly & $9(64.3 \%)$ & $5(35.7 \%)$ \\
\hline Anencephaly & $10(76.9 \%)$ & $3(23.1 \%)$ \\
\hline Dandy-Walker malformation & $4(40.0 \%)$ & $6(60.0 \%)$ \\
\hline Occipital encephalocele & $4(50.0 \%)$ & $4(50.0 \%)$ \\
\hline Agenesis of the Corpus Callosum & $2(28.6 \%)$ & $5(71.4 \%)$ \\
\hline Microcephaly & $6(100.0 \%)$ & $0(0.0 \%)$ \\
\hline Hydrocephalus & $4(66.7 \%)$ & $2(33.3 \%)$ \\
\hline Choroid plexus cyst & $1(20.0 \%)$ & $4(80.0 \%)$ \\
\hline Spina bifida (meningocele) & $1(20.0 \%)$ & $4(80.0 \%)$ \\
\hline Congenital Scoliosis & $3(75.0 \%)$ & $1(25.0 \%)$ \\
\hline Chiari malformation & $2(50.0 \%)$ & $2(50.0 \%)$ \\
\hline Schizencephaly & $2(66.7 \%)$ & $1(33.3 \%)$ \\
\hline Hydranencephaly & $1(33.3 \%)$ & $2(66.7 \%)$ \\
\hline
\end{tabular}

Table 15: Informative value of $3 \mathrm{D}$ over $2 \mathrm{D}$ in different diagnoses among the studied cases.

\section{DISCUSSION}

Central nervous system malformations are the second most frequent class of congenital anomaly, following congenital diseases of the heart. ${ }^{12}$

About $21 \%$ of congenital malformations of the CNS, including one of the most common congenital disorders and may occur either isolated or associated with other anomalies of the neural system itself or other systems. $^{3}$

Central nervous system malformation are usually severe and considered the most common indications for therapeutic abortions. ${ }^{4}$

In modern obstetrics, screening for fetal anomalies has become one of the most profile health care issues. $^{6}$
Diagnosis prenatally uses various invasive and noninvasive techniques to assess the health condition of the fetus or any disorder in intrauterine fetus. Ultrasonographic examination is an effective technique for antenatal diagnosis of these congenital anomalies. Patients usually accept this technique because it is not invasive method. An accuracy of ultrasonographic detection of CNS malformation is $92 \%$ to $99.7 \%$ according to several studies. ${ }^{12}$

In diagnosis of congenital anomalies, traditional two dimensional ultrasounds (2DUS) images may be confusing \& difficult to construct to some clinicians because they must be interpreted to form a $3 \mathrm{D}$ impression of the anatomic structures available ${ }^{14}$.

Three dimensional ultrasound (3DUS) has consider the new standard technique in antenatal diagnosis of fetal congenital anomalies. This technique allows examination of the fetal anatomy in more details and higher quality illusteration of congenital anomalies. ${ }^{8}$

Extensive and severe life threating disorders give reason for early termination of pregnancy, and detection of minor disorders helps everybody to be prepared and reassured for post-delivery management. ${ }^{4}$

The main purpose of our study is to assess the role of three dimensional (3D) ultrasound compared with two dimensional (2D) ultrasound in diagnosis of fetal central nervous system congenital malformations.

This prospective study which was performed at Obstetrics and Gynecology Department, Al-azhar University Hospital included 100 patients with gestational age from 18 weeks to 24 weeks by $2 \mathrm{D}$ ultrasound then examined by 3D ultrasound.

Each case was underwent serial transabdominal ultrasound examinations of fetal anatomy in details for detection of malformations of the neural, cardiovascular, gastrointestinal, muscloskeletal and genitourinary systems. Ultrasound examinations included transabdominal two-dimensional ultrasound examination was done first, then three-dimensional $\mathrm{U} / \mathrm{S}$ examination.

Many factors, including the experience of the investigators, can directly influence this process. In some cases of complicated fetal malformations, it can be difficult, even for experienced sonologists, to accurately determine anatomic relationships. 3D US may help to solve these problems. ${ }^{13}$

3D US acquires a sequence of 2D images at relatively equal angles and distances; these images are precisely placed in the $3 \mathrm{D}$ volume data set. ${ }^{13}$

The current study revealed that out of 100 cases, 2D US made definite diagnoses of 83 malformations $(83 \%)$. all of which were consistent with the postnatal or postmortem findings. 3D US established definite diagnoses of 88 malformations (88\%).

The current study agrees with the study by Fatma et al., (2019) which reported that 3D ultrasonography is 
effective in assessment of fetal CNS anomalies with detection of CNS anomalies on ultrasound was $90 \%$.

Our study found that the most common neurological malformations detected were Holoprosencephaly and Anencephaly which had significant high agreement between $2 \mathrm{D}$ and 3D regarding their diagnosis ( $p$ value $<0.001)$.

These findings are in agreement with previous studies of Fatma et al., (2019) which revealed that Holoprosencephaly was the most prevalent malformation (13.33\%), followed by anencephaly ( $10 \%)$ Dandy-Walker malformation $(10 \%)$ and hydrocephalus $(6.66 \%)$.

The current study revealed that there was significant agreement between $2 \mathrm{D}$ and $3 \mathrm{D}$ regarding the congenital fetal spinal and cranial malformations with $\mathrm{p}$ value $<0.001$.

The 2D and 3D ultrasound provided equal diagnostic information in microcephaly while 3D US provided more diagnostic information than 2D US for Choroid plexus cyst, corpus callosum agenesis and spina bifida (meningocele).

These results were in concordant with the study of Liu et al., (2005) which revealed that there is improved capability of 3D US to view the corpus callosum and the intracranial midline structures when compared with 2D US and 3D US visualized these structures in $78.1 \%$ of examinations; while 2D US visualized them in $3.1 \%$ of examinations. ${ }^{18}$

Our study revealed that the 3D US take the upper hand than 2D US in identifying small neurological malformations as choroid plexus cyst and Spina bifida.

These results were in agreement with the study done by Xu et al., (2002) which revealed that 3D US was superior to 2D US particularly in identifying the spine/extremities, cranium/face, malformations, and body surface explained by malformations of the cranium and spine are often associated with specific curved deformities that cannot be displayed completely on 1 cross sectional image. It is therefore difficult for conventional 2D US to display these malformations in the 3D shape and their relationships to neighboring structures. Hence, misdiagnosis and uncertain diagnosis may easily occur. ${ }^{19}$

On the contrary, Wang et al., (2000) found that 3DUS did not offer marked extra data over what was offered by 2 DUS.

These results were concordant with the results of Mohamed et al., (2000) which reported that diagnosis of a case with small spina bifida was missed on routine 2-D ultrasound examination of the low risk women and diagnosis of spina bifida after 26 weeks gestation was suspected and confirmed by $3 \mathrm{D}$ imaging.

The increasing incidence of detection of CNS congenital anomalies in recent study may be explained by increased awareness amongst treating dimensional (3D) ultrasound technology over the last years . ${ }^{6}$

Our results agreed with Dyson et al., (2000) who reported that, 3DUS introduced advantages over $2 \mathrm{D}$ US imaging in terms of diagnosis of some anomalies and data storage. However, it must be emphasized that, performing 2DUS before 3D US scanning is essential to localize the proper site for 3D scanning; consequently 3D US performance is impossible to be carried out without the prior use of $2 \mathrm{D}$ ultrasound. ${ }^{2}$

Thus, three-dimensional ultrasonography is not considered the only technique in screening but an adjunct to 2D ultrasonography for fetuses in which malformations are suspected or already determined during routine basic anomaly scan.

The main strength point of this current study is that it was done on large sample size in relation to the previous studies like $\mathrm{Xu}$ et al. (2002) which involved 41 fetuses and Fatma et al. (2019) which involved 30 cases. That helps in increase in diagnosis accuracy.

The limitations of the study are worthy of mention, The present 3D US technique still has some limitations, such as being affected by fetal motion, the amniotic fluid amount, and the orientation view.

\section{CONCLUSION}

In comparison with 2D US, 3D US improves the ability of diagnosis by introducing more information in diagnosis during fetal malformations evaluation, especially in illusteration of fetal small cranial anomalies and spina bifida. 3D US is a valuable adjunct to 2D US in prenatal diagnosis.

Three-dimensional ultrasonography is not considered the only technique in screening but an adjunct to 2D ultrasonography for fetuses in which malformations are suspected or already determined during routine basic anomaly scan

Two dimensional ultrsonography remains the gold standard in assessment of fetal anomalies, and the three dimensional ultrasonography is not considered a screening technique alone but an adjunct to two dimensional ultrasonography for fetuses in whom disorders are suspected or already determined during routine anomaly scan of the fetus .

We recommend the adjunctive use of 3-D ultrasonography with the 2-D mode in selective cases to increase diagnostic accuracy of congenital mal formation.

\section{REFERENCES}

1. Abu-Rustum RS: A Practical Guide to 3D Ultrasound. Boca Raton, FL. Taylor \& Francis Group;2014, 154-67. 
2. Baba K, Takashi O, Kozuma S, et al. Fetal abnormalities: Evaluation with real time processible three-dimensional US-Preliminary Report. Radiology 1999; 211:441-446.

3. Barros ML, Fernandes DA, Melo EV, et al. Central nervous system malformations and associated defects diagnosed by obstetric ultrasonography. Radiologia Brasileira; 2012, 45(6): 309-14.

4. Bornstein E, Rodríguez J L, Pavón E C, et al. First -Trimester Sonographic Findings Associated With a Dandy-Walker Malformation and Inferior Vermian Hypoplasia. Journal of Ultrasound in Medicine; 2013, 32(10): 1863-8.

5. Dyson RL, Pretorius DH, Budorick NE, et al. Three dimensional ultrasound evaluation of fetal anomalies. J.Ultasound ObstetGynecol. 2000; 16:321-8.

6. Fatma Salah El-Dein Mohammed, Wafaa Raafat Abdel Hamid and Ahmed Bassiony Bassiony Elsayed: Role of 3D /4D Ultrasound in Assessment of Fetal CNS Congenital Anomalies. Nat Sci 2019;17 (11):154-157].

7. Harris BS, Bishop KC, Kemeny HR, et al. Risk factors for birth defects. Obstetrical \& gynecological survey; 2017, 72(2): 123-35.

8. Kurjak A. 3D/4D Sonography. Journal of perinatal medicine. 2017 Aug 28;45(6):639-41.

9. Liu IF, Chang $\mathrm{CH}, \mathrm{Yu} \mathrm{CH}$, et al. Prenatal diagnosis of fetal acrania using threedimensional ultrasound. Ultrasound Medicine \& Biology 2005; 31(2):175-8.

10. Merz E and Welter C. 2D and 3D Ultrasound in the evaluation of normal and abnormal fetal anatomy in the second and third trimesters in a level III center. Ultraschall in der MedizinEuropean Journal of Ultrasound; 2005, 26 (01): 9-16.

11. MOHAMED N.H. and SIOUDI S.A.: Two dimensional and three dimensional ultrasonography in assessment of fetal malformation: routine versus selective use. The Egyptian Journal of Hospital Medicine Dec., $18-32,2000$
12. Monteagudo A, Timor-Tritsch IE and Levine D. Prenatal diagnosis of CNS anomalies other than neural tube defects and ventriculomegaly. Uptodate, Barss, VA (Ed), UpToDate, Waltham, MA; 2017, 235-47.

13. Nelson TR Pretorius DH. Three-dimensional ultrasound imaging. Ultrasound Med Biol 1998;24:1243.

14. Platt LD and Santulli T, Carlson E, et al. Three Dimensional ultrasonography in obstetrics\& Gynaecology: Preliminary experience, Am. J. of Obst. Gynecol. 2008; 178:1198-2006.

15. Rizzo G, Capponi A and Pietrolucci M. An algorithm based on Omniview technology to reconstruct sagittal and coronal planes of fetal brain from volume datasets acquired by three dimensional ultrasound. Ultrasound in obstetrics and Gynecology; 2011, 38: 158- 164.

16. Sharma S, Kaur N, Kaur K, et al. Role of echocardiography in prenatal screening of congenital heart diseases and its correlation with postnatal outcome. Journal of clinical and diagnostic research: JCDR; 2017, 11(4): TC12.

17. Stevenson RE, Seaver LH and Collins JS. Neural tube defects and associated anomalies in South Carolina. Birth Defects Research Part A : Clinical and Molecular Teratology; 2004, 70: 554-8.

18. Wang PH, Ying TH, Wang PC, et al. Obstetric three dimensional ultrasound in the visualization of the intracranial midline and corpus callosum of fetuses with cephalic position. Prenatal Diagnosis 2000; 20:518-20.

19. Xu HX, Zhang QP, Lu MD, et al. Comparison of two-dimensional and three-dimensional sonography in evaluating fetal malformations. J Clin Ultrasound. 2002;30 (9):515-25. 